Article

\title{
Study on an Improved Phosphate Cement Binder for the Development of Fiber-Reinforced Inorganic Polymer Composites
}

\author{
Zhu Ding ${ }^{1, *}$, Jian-Guo Dai ${ }^{2, \dagger}$ and Sarfraz Muner ${ }^{2, \dagger}$
}

1 School of Civil Engineering, Shenzhen University, Shenzhen 518060, China

2 Department of Civil and Environmental Engineering, the Hong Kong Polytechnic University, Hong Kong, China; E-Mails: cejgdai@polyu.edu.hk (J.-G.D.); sarfrazmuner@yahoo.com (S.M.)

$\dagger$ These authors contributed equally to this work.

* Author to whom correspondence should be addressed; E-Mail: zding@szu.edu.cn;

Tel./Fax: +86-755-2673-2834.

Received: 28 July 2014; in revised form: 30 October 2014 / Accepted: 30 October 2014 /

Published: 12 November 2014

\begin{abstract}
Magnesium phosphate cement (MPC) has been proven to be a very good repair material for deteriorated concrete structures. It has excellent adhesion performance, leading to high bonding strength with old concrete substrates. This paper presents an experimental study into the properties of MPC binder as the matrix of carbon fiber sheets to form fiber-reinforced inorganic polymer (FRIP) composites. The physical and mechanical performance of the fresh mixed and the hardened MPC paste, the bond strength of carbon fiber sheets in the MPC matrix, the tensile strength of the carbon FRIP composites and the microstructure of the MPC matrix and fiber-reinforced MPC composites were investigated. The test results showed that the improved MPC binder is well suited for developing FRIP composites, which can be a promising alternative to externally-bonded fiber-reinforced polymer (FRP) composites for the strengthening of concrete structures. Through the present study, an in-depth understanding of the behavior of fiber-reinforced inorganic MPC composites has been achieved.
\end{abstract}

Keywords: magnesium phosphate cement (MPC); concrete; inorganic binder; fiber-reinforced polymer (FRP) 


\section{Introduction}

Portland cement concrete structures could be deteriorated during service by loading and various environmental effects. To these deteriorated concrete structures, bonding external fiber-reinforced polymer (FRP) composites to the concrete substrates has become a very popular strengthening technique in recent years. FRP composites have many advantages, such as a high strength-to-weight ratio, excellent corrosion resistance and a fast-curing property. However, FRP composites possess some weakness. For instance, they have poor resistance to fire and high temperature, because of the use of organic polymer binders (commonly an epoxy resin) as the matrix of the fibers. Consequently, this limits its use in many construction applications [1,2]. In addition, the polymer binders form a sealed coating on the concrete surface that prevents the exchange of moisture, leading to the incompatibility of concrete and externally-bonded FRP composites. To overcome these problems, attempts have been made to develop inorganic matrix-based FRP materials for the strengthening of concrete structures. To attain ideal reinforcing effects, the inorganic matrix requires the following features [3]: (1) sufficient mechanical strength for load transfer; (2) the ability to impregnate and create a strong bond with the fiber-reinforcing materials; (3) the ability to bond strongly to the concrete substrate; (4) thermal and chemical compatibility with the concrete substrate; (5) good workability on site, including good consistency and fast-curing ability; (6) environmental acceptability; and (7) limited shrinkage.

In previous studies, four major types of inorganic matrices have been explored for the development of fiber-reinforced inorganic polymer (FRIP) composites: (1) polymer-modified mortar-based matrix (usually ordinary Portland cement mortar (PMM) [4-6]; (2) geopolymer (GP)-based matrix [7,8]; (3) magnesium oxychloride cement (MOC)-based matrix [9]; and (4) magnesium phosphate cement (MPC)-based matrix [10,11]. Among them, magnesium phosphate cement (MPC) has a very high strength, an excellent adhesion performance with other cementitious materials and a good volume stability [10,11]. However, traditional MPC, which consists of magnesia and ammonium phosphates, develops strength by a violent acid-based reaction between magnesia and phosphate solution, resulting in a very fast setting of the paste. At the same time, the traditional MPC would liberate ammonia during mixing and service, which would be harmful to the environment. Therefore, the utilization of this cement is limited. In the past several years, MPC was only used for the rapid repair of concrete structures [11].

In recent years, a new type of MPC has been developed, based on magnesium and potassium phosphate, for which no ammonia is liberated in the hydration process [12,13]. Furthermore, this type of MPC can incorporate a large volume of fly ash and other non-hazardous industrial wastes to form valuable building materials. Therefore, it is thought of as a green and sustainable inorganic binder. MPC is receiving greater attention, because of its many advantages, including quick strength development, good durability and dimensional stability, good water absorption resistance and excellent adhesion properties with old concrete substrates [11,14,15]. It is a very attractive material for the repair of concrete structures, for sealing boreholes and the solidification of hazardous wastes. In addition, MPC also has been proven to be a potential matrix for the development of FRIPs [16-18]. The objective of this paper is to further study the properties of MPC paste and mortar as the matrix to develop FRIP composites for the strengthening of concrete structures. 


\section{Experimental Program}

\subsection{Materials and Mix Proportions}

MPC binder was prepared using dead burnt magnesia (M), mono-potassium phosphate (MPP), Class F fly ash (FA), boric acid (BA) and water (W). The dead burnt magnesia used in the study is a commercially available product with $\mathrm{MgO}$ content of $83.18 \mathrm{wt} \%$ and an average particle size of $19.16 \mu \mathrm{m}$, bought from Jimei Refractories Co., LTD., Jinan, China. MPP and BA were bought from Guangzhou Chemical Reagent Co., LTD., China. The mix proportions of MPC paste are summarized in Table 1. The experimental parameters mainly include the fly ash-to-dead burnt magnesia ratio (i.e., $\mathrm{FA} / \mathrm{M}=0.4,0.5,0.6,0.8$ and 1.0 ) and the water-to-binder ratio (W/B) (i.e., $\mathrm{W} / \mathrm{B}=0.22,0.26$ and 0.30 ). The binder was defined as the sum of all of the dry powder blended by magnesia, phosphate and fly ash. After an optimized range of the fly ash content was found (i.e., FA/M = 0.6-1.0), some mix proportions for MPC mortar were also made (see Nos. 3-5 in Table 1). The addition of BA to M was 0.1 by weight. Tap water was used as the mixing water. For the production of MPC mortar, quartz sand passing through a sieve with a size of $600 \mu \mathrm{m}$ was used as the fine aggregate. Carbon fiber sheets (Figure 1) used to produce FRIP composites had a nominal thickness of $0.11 \mathrm{~mm}$ and an area weight of $200 \mathrm{~g} / \mathrm{m}^{2}$. The fiber had a tensile strength of $3400 \mathrm{MPa}$ and an elastic modulus of $240 \mathrm{GPa}$.

Table 1. Mix proportions of MPC paste and mortar (mass ratio).

\begin{tabular}{ccccc}
\hline Type & \multicolumn{2}{c}{ MPC paste/mortar } & MPC paste & MPC mortar \\
\hline No. & FA:M & W:(FA + M + P) & MPP:M & MPP:M:Sand \\
1 & 0.4 & 0.22 & $1: 1$ & None \\
2 & 0.5 & 0.22 & $1: 1$ & None \\
3 & 0.6 & 0.22 & $1: 1$ & $1: 1: 1$ \\
4 & 0.8 & 0.22 & $1: 1$ & $1: 1: 1$ \\
5 & 1.0 & 0.22 & $1: 1$ & $1: 1: 1$ \\
6 & 1.0 & 0.26 & $1: 1$ & None \\
7 & 1.0 & 0.30 & $1: 1$ & None \\
\hline
\end{tabular}

\subsection{Test Methods}

In this study, test specimens of MPC were paste and mortar, respectively. The procedures for preparing MPC paste and mortar specimens are as follows: the phosphate, magnesia, fly ash and boric acid were weighed, respectively, put into a pot and then uniformly mixed in a dry state. In the case of MPC mortar, sand was further added in and uniformly mixed. Then, the mixing water was added into the pot. In the case of the MPC paste, the mixing was completed by hand operation using a spoon for two minutes. In the case of the MPC mortar, the mixing was conducted by a mortar mixer $(80 \pm 4 / \mathrm{min})$ and lasted for two minutes.

To determine the fluidity of freshly mixed MPC paste, a mini-cone slump flow test was used [19,20], with an upper diameter of $36 \mathrm{~mm}$, a lower diameter of $60 \mathrm{~mm}$ and a height of $60 \mathrm{~mm}$ (Figure 1). The diameter of the circle of the MPC paste, which then flowed over the horizontal glass plate, was measured. The setting time of the paste was determined using a Vicat needle following ASTM (American Society for Testing and Materials) C-191. 
Figure 1. Mini-cone slump test.

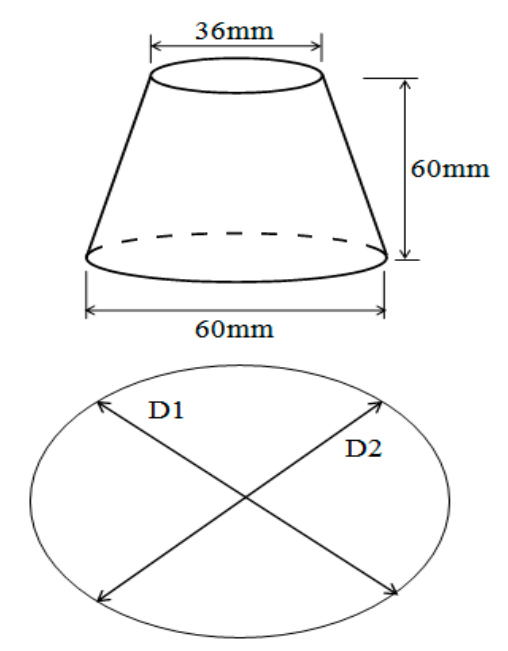

The compressive strength of MPC paste and mortar was determined based on $30 \mathrm{~mm} \times 30 \mathrm{~mm} \times 30 \mathrm{~mm}$ cube specimens. The compressive strengths were obtained after 1, 3, 7 and 28 days of curing. The flexural strength of each MPC paste was determined using prisms with dimensions of $40 \mathrm{~mm} \times 40 \mathrm{~mm} \times 160 \mathrm{~mm}$ and following ASTM C-348.

Pullout tests were performed to evaluate the bond performance of carbon fiber sheets in different MPC paste matrices. The specimens were prepared in the form of a $70.7 \mathrm{~mm} \times 70.7 \mathrm{~mm} \times 70.7 \mathrm{~mm}$ cube in which one layer of dry carbon fiber sheet was embedded at the center, as shown in Figure 2. For the purpose of exerting uniform stresses into the fiber sheets during the pullout tests, the fiber sheets of the cubes were impregnated with a two-part epoxy matrix, Lica ${ }^{\circledR}-100 \mathrm{~A} / \mathrm{B}$, supplied by Haite Company (Chengdu, Sichuan, China), of which the ratio of the resin to hardener was $2: 1$ by weight.

Figure 2. Pullout test specimen.

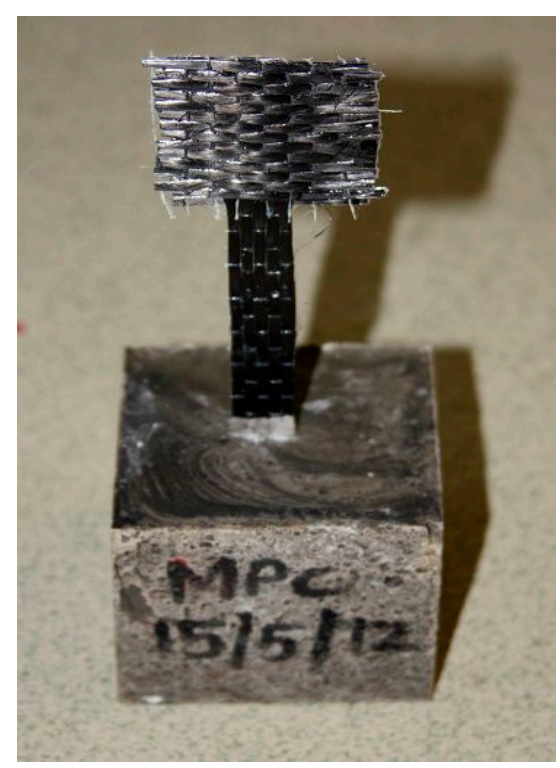

The tensile strength of MPC-based FRIP composites was evaluated using a specimen, as shown in Figure 3. It was $3 \mathrm{~mm}$ in thickness and made in a dumbbell shape. The fiber sheets were sandwiched in the specimen. The two ends of the tensile specimen were also impregnated with epoxy to avoid local 
failure between the head and the center part. Tensile tests were conducted after 7 days of curing, using a universal testing machine with a strain rate of $1 \mathrm{~mm} / \mathrm{min}$.

Figure 3. Tensile test specimens.

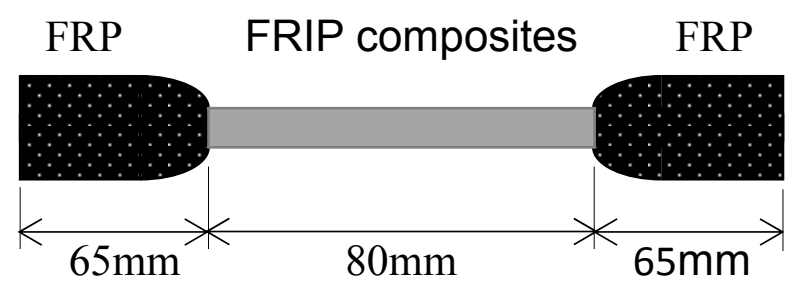

For all of the above MPC test specimens, three identical specimens were prepared for each combination of testing parameters. The average strength of the three specimens was presented for discussion. All of the specimens were demolded after $24 \mathrm{~h}$ and cured in an environment with a temperature of $25 \pm 2{ }^{\circ} \mathrm{C}$ and relative humidity of $55 \% \pm 5 \%$. All of the mix proportions in Table 1 were tested for the fluidity, initial setting time and compressive strength. Compressive, flexural, pullout and tensile strengths were conducted on MPC paste specimens for mix Nos. 1-5 in Table 1, while compressive and flexural tests were conducted on MPC mortar specimens for mix Nos. 3-5.

\section{Results and Discussion}

\subsection{Physical Properties of MPC Paste}

In FRIP composites, the inorganic paste becomes the matrix to bind fibers after hardening. Therefore, its workability plays a very important role in the performance of FRIP composites. In the case of the MPC paste, its workability needs improvement, so as to provide sufficient setting time for the formation of the fiber composites. In this study, boric acid $\left(\mathrm{H}_{3} \mathrm{BO}_{3}\right)$ was used to increase the setting time of MPC. Mix Nos. 1-5, which had a W/B ratio of 0.22 achieved a similar initial setting time of around $25 \mathrm{~min}$.

A higher fluidity of the MPC paste is desired so that higher impregnation of the paste into the fibers can be achieved, leading eventually to better bonding between the fibers and the matrix, as well as the higher tensile strength of the formed FRIP composites. In the meantime, the flow of the MPC paste should also be sticky enough to be applied on the vertical surfaces of columns and soffit of beams/slabs for strengthening applications. Figure 4 presents the fluidity results of fresh MPC pastes. The fluidity of MPC paste depends mainly on the water content of the paste [18]. Obviously, the flow of MPC pastes increases with the water content. However, such a way for increasing the flow may bring some adverse effects to other properties, such as the strength. In the present tests, when the W/B ratio was fixed at 0.22 , fly ash was used as the filler to adjust the flow of MPC pastes.

Figure 4 shows the relationship between the flow and the FA/M ratio. It seems that the flow of fresh MPC paste increases with the FA/M ratio and gained an optimized value when the latter reached the value of 0.8. Afterwards, the flow decreased. This behavior might be attributed to the small and spherical grains of FA, which helps to flow the MPC paste at relatively low water contents. However, when the FA/M ratio is too high, the same water content may not be enough to lubricate the binder, resulting in a decreased flow. 
Figure 4. The effect of fly ash (FA) on the flow of MPC paste.

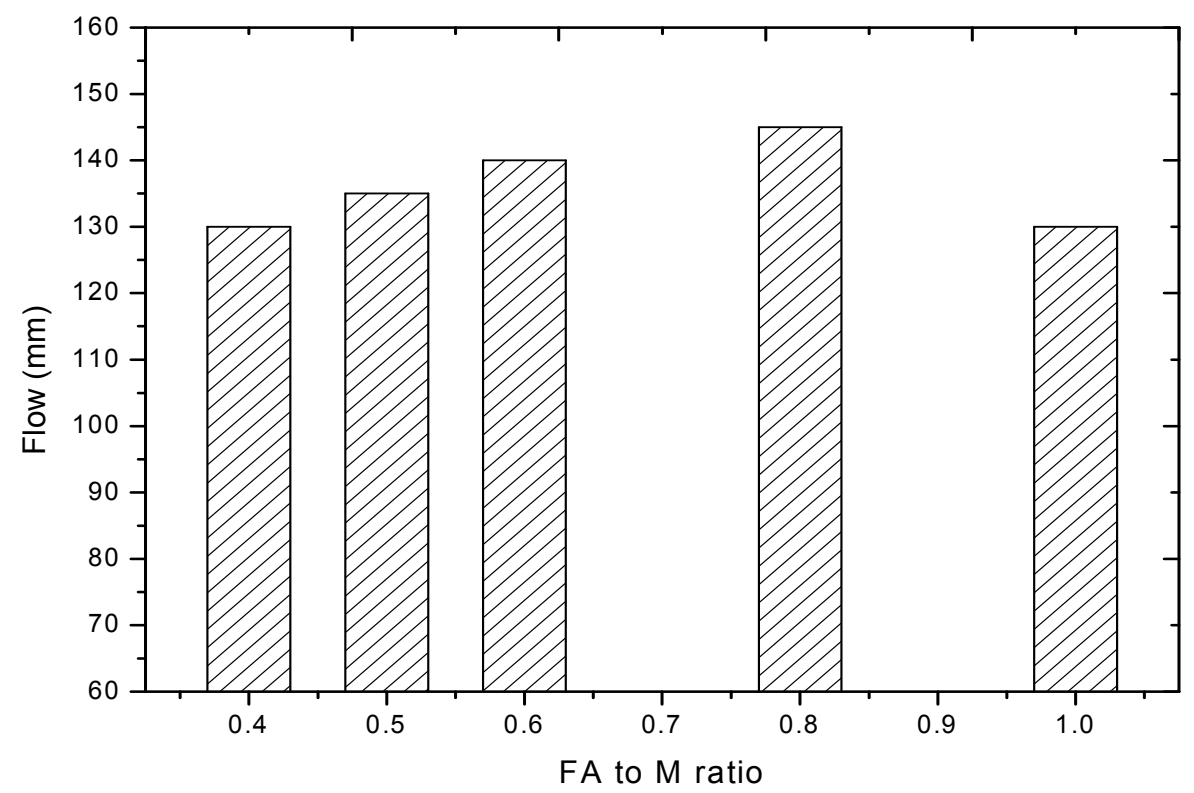

\subsection{Mechanical Properties of MPC Paste/Mortar}

\subsubsection{Compressive Strength}

The compressive strength of MPC pastes depends on many factors, like the fineness of magnesia, the $\mathrm{M} / \mathrm{P}$ (magnesia/phosphate) ratio, the $\mathrm{W} / \mathrm{B}$ ratio and FA content. The M/P ratio also has an effect on the setting time of MPC pastes. In this study, the M/P ratio was selected as 1.0 to ensure an adequate strength with reasonable setting time. Figure 5 shows the compressive strength development of MPC pastes with time for three different W/B ratios. As expected, a lower W/B ratio results in higher strength and vice versa. The strength drops evidently when the water content increases. A W/B ratio of 0.22 led to approximately a 28-day compressive strength of $45 \mathrm{MPa}$ and a 1-day strength of $20 \mathrm{MPa}$. Such an early strength is very suited for the development of strengthening materials.

Figure 5. Compressive strength of MPC pastes.

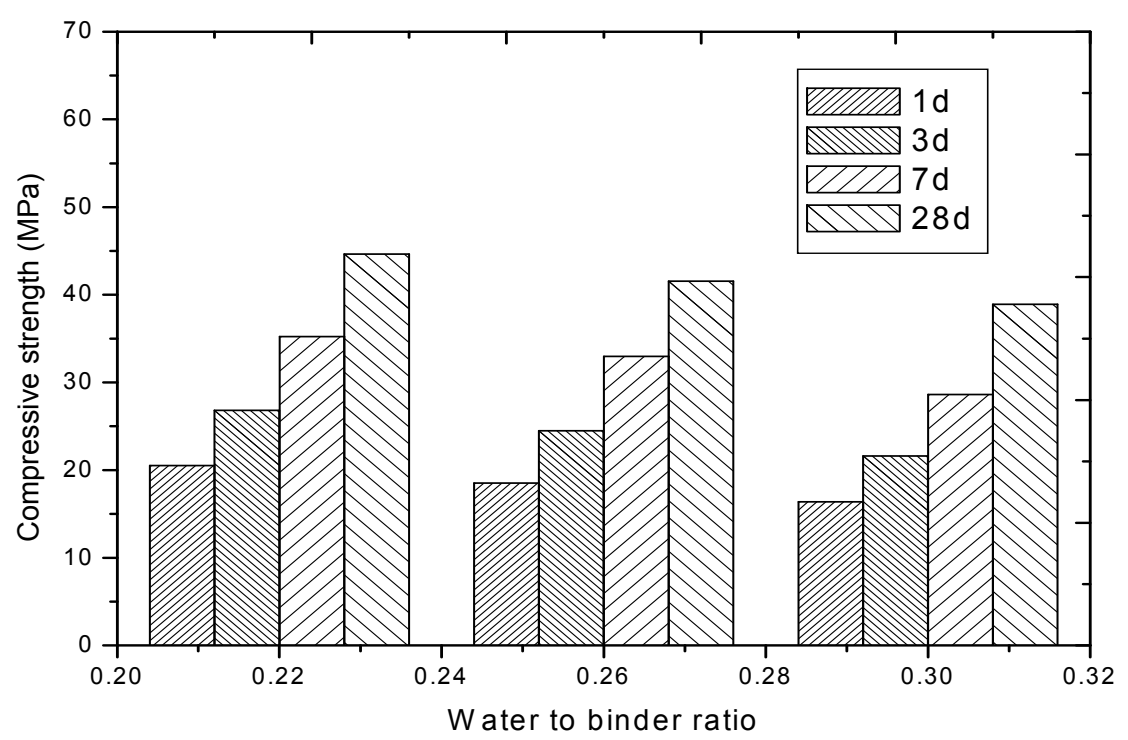


The effect of FA content on the compressive strength of MPC pastes was also studied. The compressive strength of MPC paste increases with FA/M, until its value reaches 0.8 and then decreases (Figure 6). This behavior might be attributed to better compaction of MPC by the micro-sized particles of FA [13]. In the case of MPC mortar, since sand and FA acted as the filler, the addition of FA to the MPC mortar increased the amount of filler in the mix, resulting in a decrease in the compressive strength (Figure 7). The strength development with time also decreased with the increase of the filler content by reducing the reaction rate between magnesia and phosphate solution in the MPC mortar.

Figure 6. The effect of FA content on the compressive strength of MPC paste.

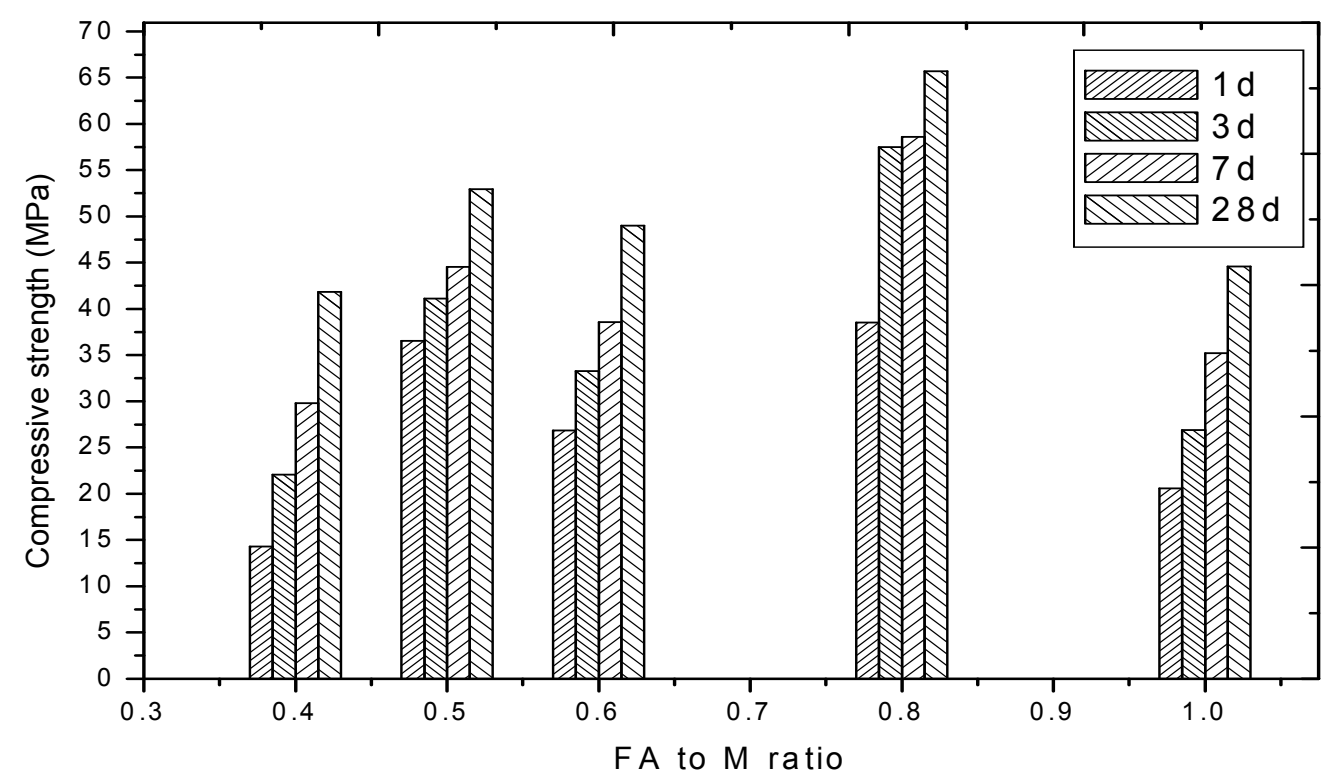

Figure 7. The effect of FA content on the compressive strength of MPC mortar $(\mathrm{W} / \mathrm{B}$ (water:binder) $=0.22$ ).

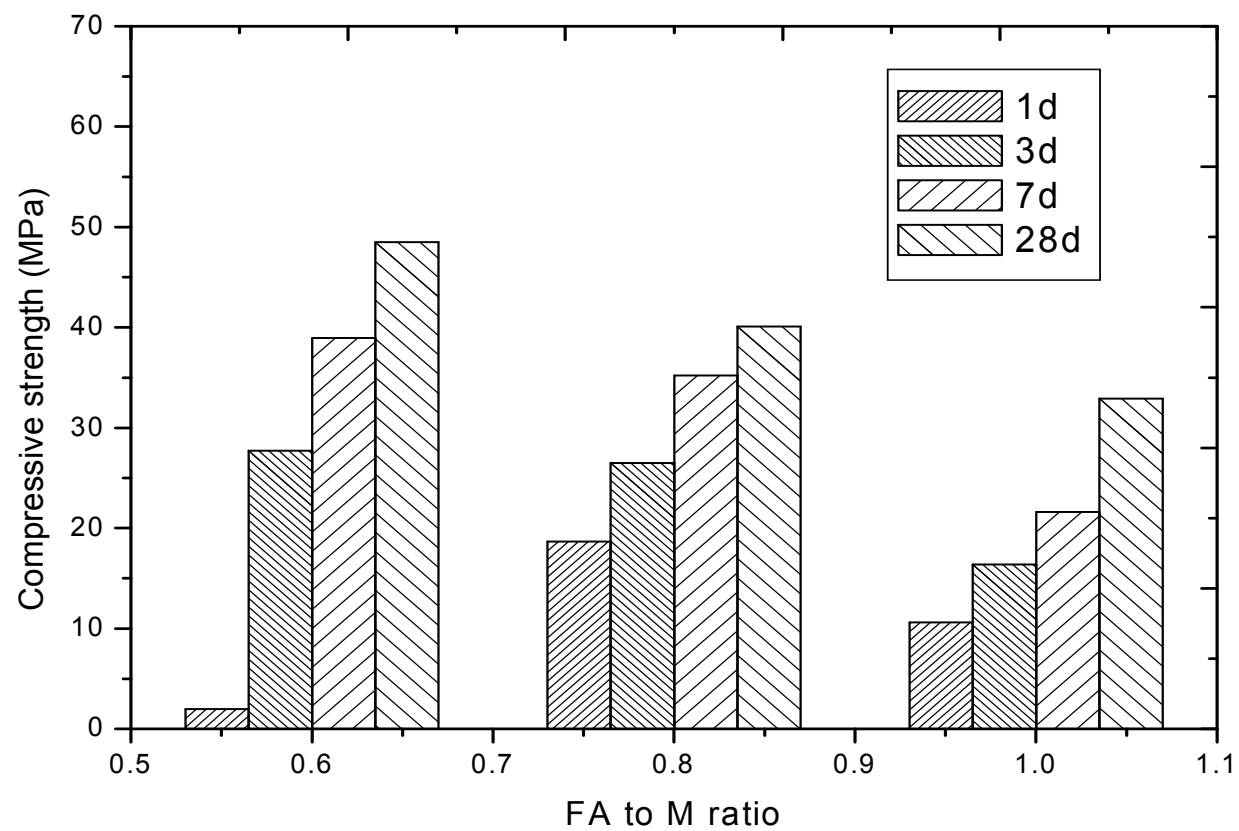




\subsubsection{Flexural Strength}

Flexural strength is an indirect measure of the tensile strength of the MPC pastes. The present tests showed that the MPC mortar achieved higher flexural strength than its paste counterpart (Figure 8). The higher strength of MPC mortars might be due to the high density of sand particles, which increased the toughness of the pastes and resulted in higher flexure strength. The flexural strength for different mix proportions of MPC pastes was tested at seven days. An increase in the flexural strength of MPC pastes was observed with the increase of FA content up to $80 \%$ by weight of dead burnt magnesia, and then, a decrease was observed (Figure 8). This was similar to the compressive strength of MPC pastes. The flexural strength of MPC mortar was higher than that of MPC pastes, and it keeps increasing with the FA content.

Figure 8. Flexural strength (at 7th day) of MPC pastes and MPC mortars.

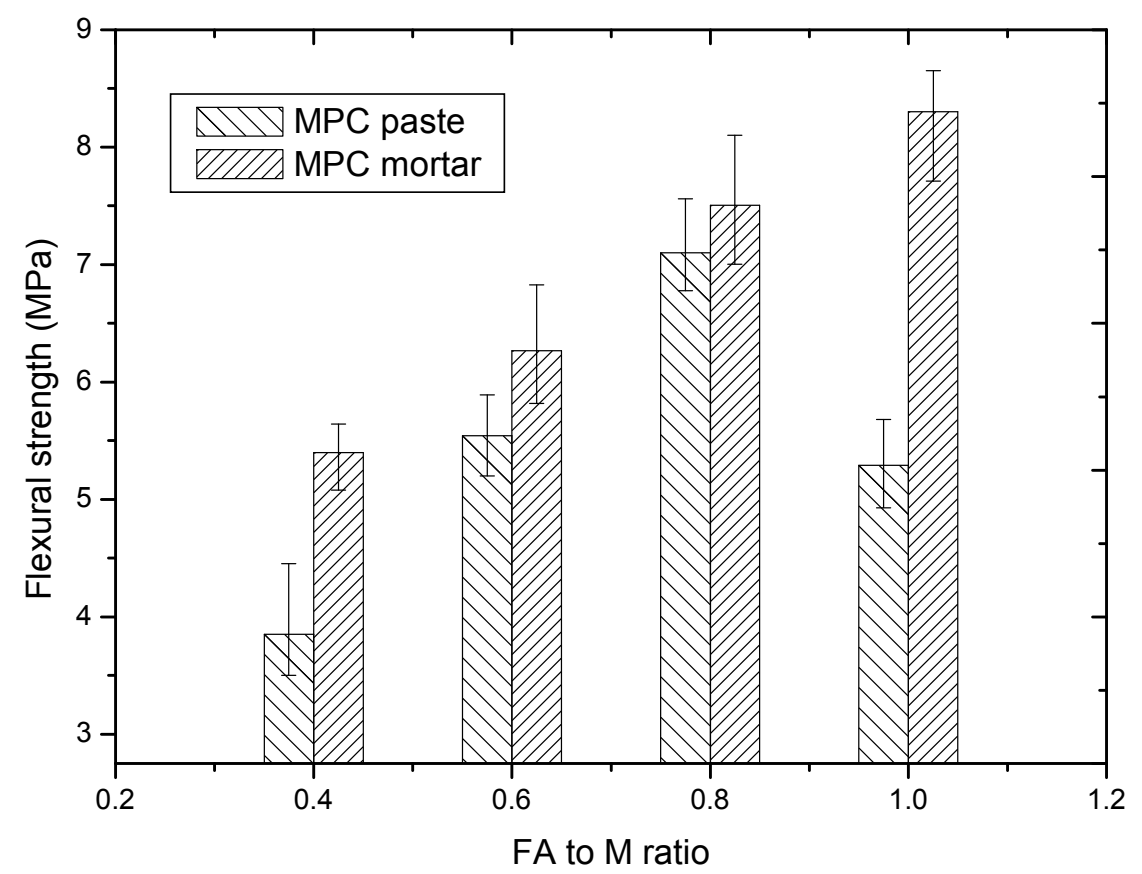

\subsection{Mechanical Properties of MPC-Based FRIP Composites}

\subsubsection{Pullout strength of fiber sheets}

In order to determine the bond strength of carbon fiber sheets in the MPC paste matrix, pullout tests were conducted. The bond strength influences the effectiveness of the fibers in the inorganic matrix. In the tests, fiber sheets were embedded in a $70.7 \mathrm{~mm} \times 70.7 \mathrm{~mm} \times 70.7 \mathrm{~mm}$ cube of MPC paste, and after seven days of curing, fiber sheets were pulled out of the MPC matrix using a universal testing machine. The pullout bonding strength was then calculated by dividing the ultimate force by the surface area of the fiber sheets embedded in the matrix. Figure 9 shows the effect of the FA-to-M ratio on the pullout strength of carbon fiber sheets. In Figure 9, the MPC matrix samples have a similar pullout strength within an $\mathrm{F} / \mathrm{M}$ ratio of 0.4 to 1.0 . It is indicated that the FA content has an insignificant effect on the pullout strength in a larger F/M ratio range, probably due to the good fluidity of the paste attached to this mix proportion, as discussed previously (Figure 4). 
Figure 9. The pullout strength of carbon fiber composites with different FA additions.

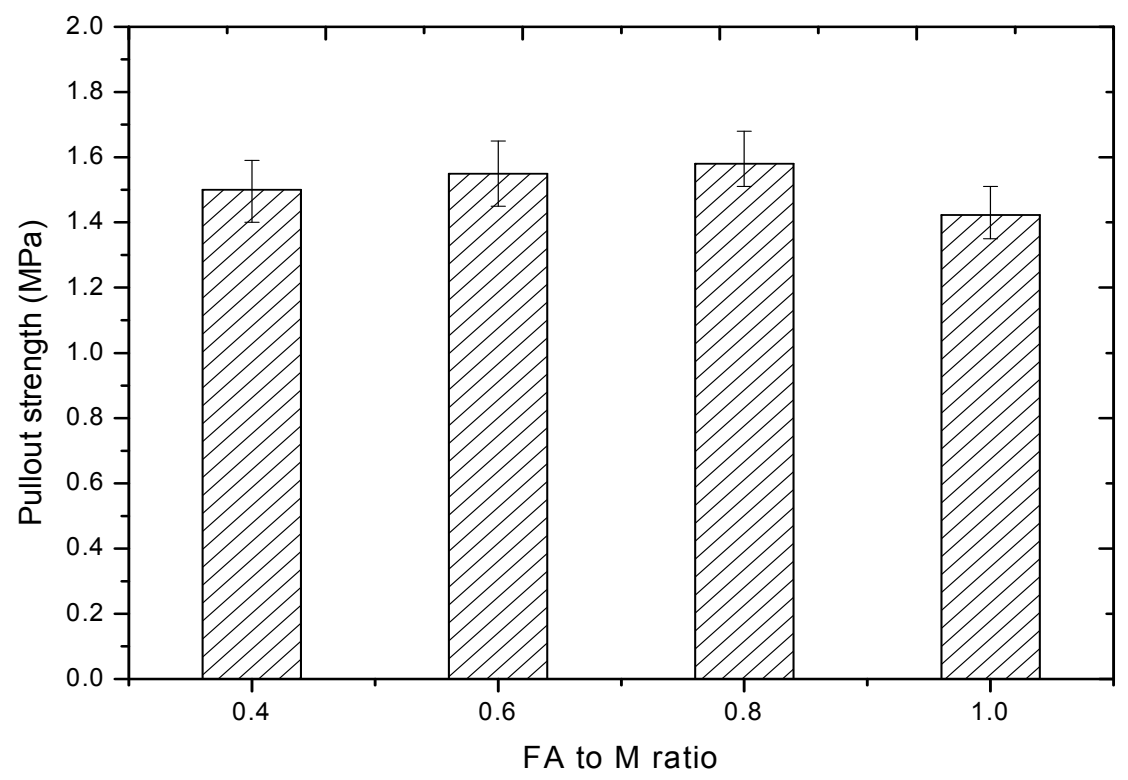

\subsubsection{Tensile Strength of MPC-Based FRIP Composites}

The tensile strength of FRIP composites is one of the most important parameters for such an inorganically-bonded strengthening system. The tensile strength of MPC-based FRIP composite was tested with the FA/M ratio ranging from 0.4 to 1.0. The variation of the tensile strength (seven days) with the FA/M ratio is presented in Figure 10. It can be observed that the tensile strength of fiber sheets in the MPC matrix decreased by $15 \%$ when the FA/M ratio increased from 0.4 to 1.0 . This trend is slightly different from that of the pullout strength. Such a decrease may be attributed to the increase in the filler material (FA), which reduces the impregnation of the matrix into the fibers. During the loading, a first crack perpendicular to the load direction appeared in the MPC matrix at the central part at a load of nearly $60 \%$ of the ultimate load. Sometimes, multiple cracks perpendicular to the load direction appeared in the MPC matrix.

Figure 10. The tensile strength of MPC-based carbon FRIP composites.

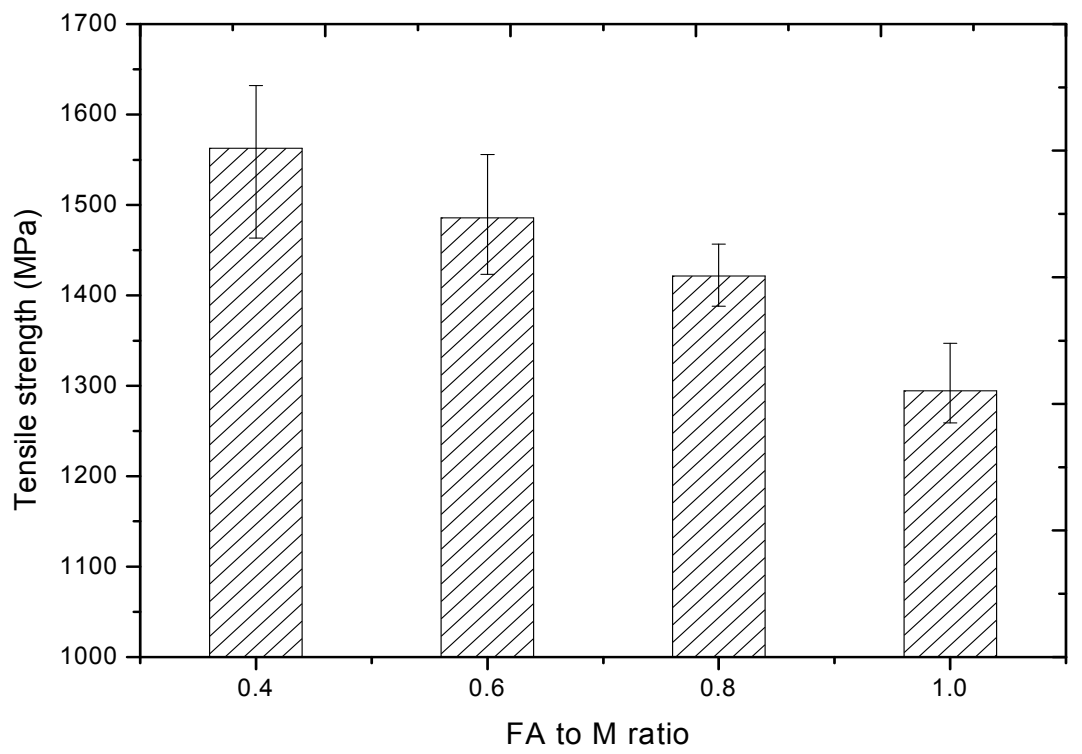




\subsection{Microscopic Observations}

\subsubsection{XRD Analysis}

XRD (X-ray diffraction) analysis of the MPC paste was conducted at 28 days. In the XRD analysis, various peaks indicated a high level of the crystalline phase of the MPC paste (Figure 11). These peaks referred to two types of crystalline compounds: one compound is identified as unreacted magnesia $(\mathrm{MgO})$; the other was formed from $\mathrm{MgKPO}_{4} \cdot 6 \mathrm{H}_{2} \mathrm{O}(\mathrm{MKP})$, which is the reaction product of MPC with water. Some other phases of diffused peaks can also be found in the XRD pattern, which represent the amorphous phases of $\mathrm{MgKPO}_{4} \cdot 6 \mathrm{H}_{2} \mathrm{O}$. Therefore, both crystalline dead burnt magnesia $(\mathrm{MgO})$ and MKP, as well as the amorphous phases of MKP were present in the MPC paste. This is a highly favorable combination and can result in a more compacted and dense microstructure.

Figure 11. XRD of MPC paste.

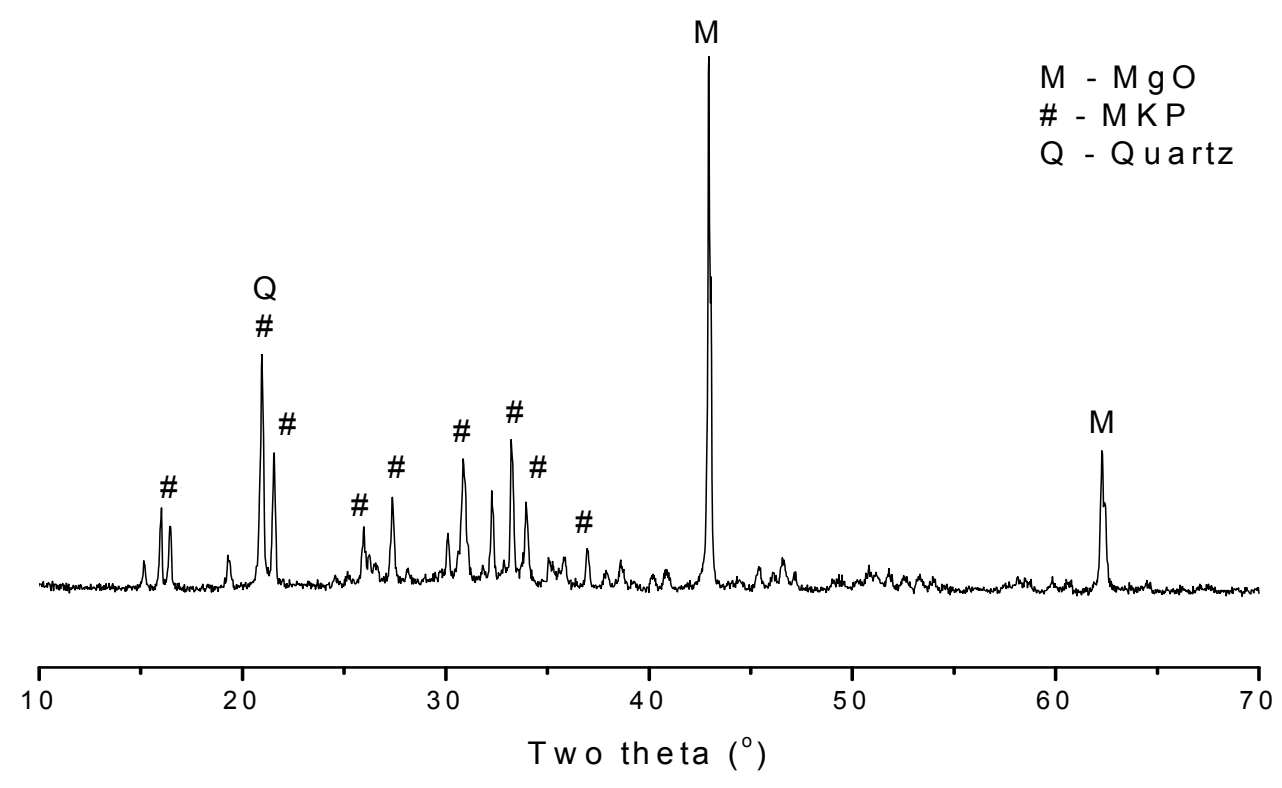

\subsubsection{SEM Analysis of MPC Pastes}

SEM (scanning electronic microscope) analysis of the MPC paste matrix was performed at 28 days. Figure 12 shows the micrographs of hardened MPC paste. In Figure 12a, it shows the dense and acicular structure of the MPC hydration product (i.e., MKP). There are also FA particles found in the diagrams, Figure 12b. MKP is the main component for developing the high strength, while FA particles and the residual magnesia act as the filler in the MPC paste. Therefore, the well-compacted structure resulted in the high mechanical strength of MPC pastes. Figure 12a shows the fiber hydrate products in paste, and Figure $12 \mathrm{~b}$ shows the fly ash particles in MPC paste as fine aggregates. These very fine cracks are the original cracks during the microstructure formation, like in the hardened Portland cement paste. 
Figure 12. SEM of MPC paste matrix. (a) Acicular hydrate products in paste; (b) Fly ash particle in the paste.

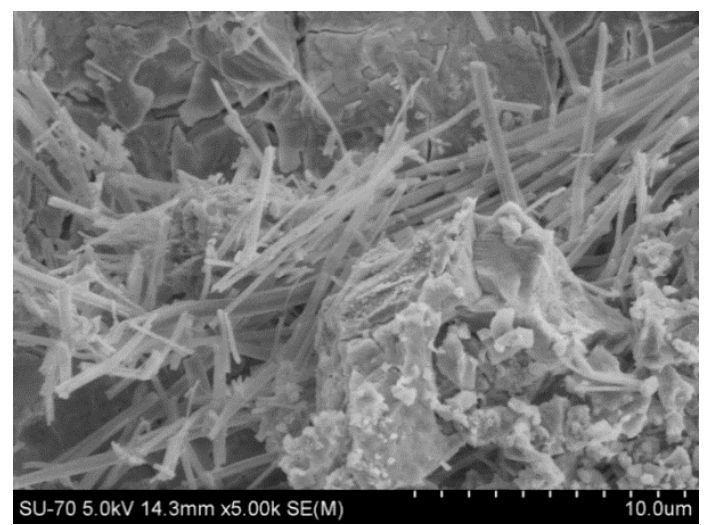

(a)

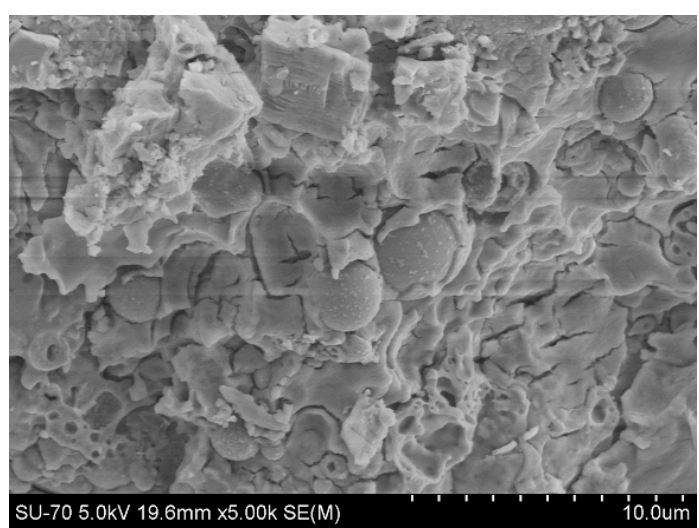

(b)

\subsubsection{SEM Analysis of FRIP Composites}

The SEM photos of MPC-based FRIP composites also show the interlocking of fibers with the MPC pastes (Figure 13). The SEM picture was taken from a specimen after failure; the surface was slightly ground before the observation. The SEM analysis was also performed at 28 days, so a relatively higher volume of hydration products could be observed. The penetration of MPC pastes into the fibers and the above-mentioned interlocking effect benefit the bond between the fibers and the matrix, confirming the suitability of using MPC for the development of FRIP composites for the purpose of structural strengthening of concrete structures.

Figure 13. SEM of MPC-based FRIP composites.

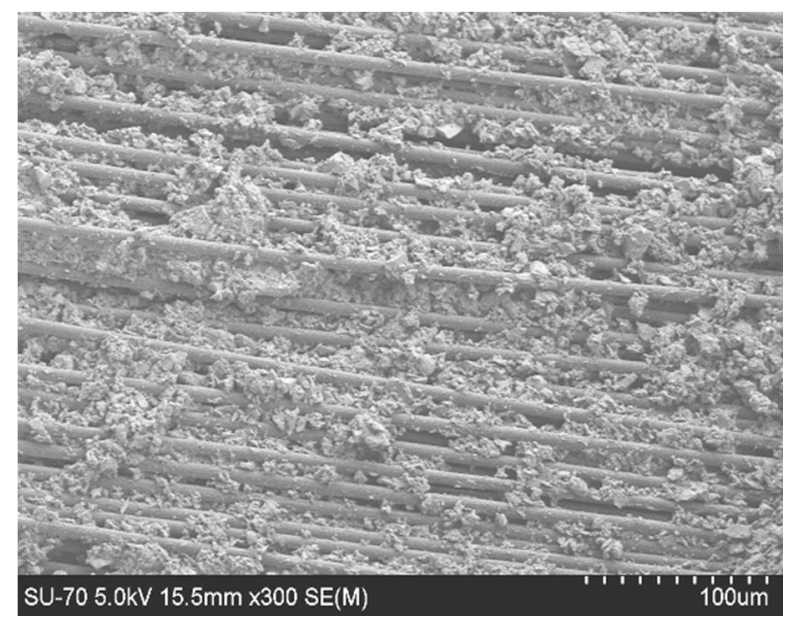

\section{Conclusions}

Based on the current experimental investigations, the following conclusions can be drawn:

1. The workability of fresh mixed MPC paste was improved and an initial setting time of around 25 min was achieved by using the boric acid when the W/B ratio was 0.22 . The flow of the MPC paste reached up to $145 \mathrm{~mm}$ when the addition of $\mathrm{FA}$ was $80 \%$ by the weight of magnesia. The improved workability of MPC paste can allow its use in situ. 
2. The compressive strength development of MPC paste and mortar samples was determined respectively. The compressive strength is inversely proportional to the $\mathrm{W} / \mathrm{B}$ ratio. When the W/B ratio was fixed, the compressive strength of the MPC paste reached its peak value when the fly ash-to-magnesia ratio (FA/M) is 0.8 . However, in the case of MPC mortar, the samples with $\mathrm{FA} / \mathrm{M}=0.6$ had the highest compressive strength.

3. The flexural strength for different mix proportions of MPC pastes and mortar was tested at 7 days. The MPC mortar exhibited higher flexural strength than the MPC paste given the same W/B ratio. The reason is that the high density of sand particles increased the toughness of the pastes. An increase in the flexural strength of MPC pastes was also observed with the increase in the FA/M ratio up to 0.8 .

4. Pullout tests were conducted to determine the bond strength of carbon fiber sheets in the MPC matrix. FA has shown an insignificant effect on the pullout strength of fiber sheets when the FA/M ratio increased from 0.4 to 1.0 by weight in the current study. The tensile strength of MPC-based carbon FRIP composites was also tested. The tensile strength of the FRIP composites decreased in sequence when the FA/M ratio increased from 0.4 to 1.0.

5. According to the XRD analysis, unreacted magnesia $(\mathrm{MgO})$ and both crystal and amorphous forms of $\mathrm{MgKPO}_{4} \cdot 6 \mathrm{H}_{2} \mathrm{O}$ (MKP) can be identified in the MPC matrix. SEM analyses of hardened MPC pastes showed a dense and acicular structure, which was formed by these crystals, amorphous products and fly ash particles. The micrograph of MPC-based FRIP composites also showed good impregnation of MPC pastes in the fibers, but the bond between fibers and the MPC matrix needs to be improved in a future study.

\section{Acknowledgments}

The authors are grateful for the financial support received from the National Natural Science Foundation of China (Project Code: 51172146) and the Research Grants Council of Hong Kong Special Administrative Region (SAR) (Project No: Poly U 5145/13E), as well as for the research fund supported by Shenzhen Strategic Emerging Industry Development Special Fund Project (JCYJ20120613104803576).

\section{Author Contributions}

Zhu Ding was responsible for developing the study plan, working on some experimental measurement and contributed to the paper drafting. Jian-Guo Dai was also responsible for developing the study plan and contributed to the revision of the paper draft. Sarfraz Munir conducted the experimental tests.

\section{Conflicts of Interest}

The authors declare no conflict of interest.

\section{References}

1. Harries, K.A.; Porter, M.L.; Busel, J.P. FRP materials and concrete-Research needs. Concr. Int. 2003, 25, 69-74.

2. Keller, T.; Tracy, C.; Huge, E. Fire endurance of loaded and liquid-cooled GFRPslabs for construction. Compos. A Appl. Sci. Manufact. 2006, 37, 1055-1067. 
3. Wiberg, A. Strengthening of Concrete Beams Using Cementitious Carbon Fibre Composites. Ph.D. Thesis, Royal Institute of Technology, Stockholm, Sweden, 2003.

4. Trapko, T. The effect of high temperature on the performance of CFRP and FRCM confined concrete elements. Compos. B Eng. 2013, 54, 138-145.

5. Wang, K.; Young, B.; Smith, S.T. Mechanical properties of pultruded carbon fibre-reinforced polymer (CFRP) plates at elevated temperatures. Eng. Struct. 2011, 33, 2154-2161.

6. Hashemi, S.; Al-Mahaidi, R. Experimental and finite element analysis of flexural behavior of FRP-strengthened RC beams using cement-based adhesives. Constr. Build. Mater. 2012, 26, $268-273$.

7. Fang, Z.Z.; Wu, C.W.; Sun, T.F.; Wu, M.X. Applying geopolymer-bonded fibrepastes to RC beam to enhance shear reinforcement. J. Build. Mater. 2009, 12, 361-365. (In Chinese)

8. Zheng, W.Z.; Chen, W.H.; Xu, W.; Wang, Y. Experimental research on alkali-activated slag high temperature resistant inorganic adhesive pasting CFRP sheets on surface of concrete. J. Build. Mater. 2009, 30, 138-145. (In Chinese)

9. Zhang, X.; Li, S.B.; Yang, W.L. Experimental study on flexural behavior of RC beams strengthened with inorganic adhesive CFRP sheets. J. Build. Struct. 2010, 2, 249-254. (In Chinese)

10. Sarkar, A.K. Hydration/dehydration characteristics of struvite and dittmaritepertaining to magnesium ammonium phosphate cement system. J. Mater. Sci. 1991, 26, 2514-2518.

11. Yang, Q.B.; Zhang, S.; Wu, X.L. Deicer-scaling resistance of phosphate cement-basedbinder for rapid repair of concrete. Cem. Concr. Res. 2002, 32, 165-168.

12. Wagh, A.S.; Jeong, S.Y. Chemically bonded phosphate ceramics: A dissolution model of formation. J. Soc. 2003, 86, 1838-1844.

13. Ding, Z.; Li, Z.J. High-early-strength magnesium phosphate cement with fly ash. ACI Mater. J. 2005, 102, 375-381.

14. Li, Y.; Chen, B. Factors that affect the properties of magnesium phosphate cement. Constr. Build. Mater. 2013, 47, 977-983.

15. Ding, Z.; Dong, B.; Xing, F.; Han, N.X.; Li, Z.J. Cementing mechanism of potassium phosphate based magnesium phosphate cement. Ceram. Int. 2012, 38, 6281-6288.

16. Ding, Z.; Lu, Z.X.; Li, Y. Feasibility of basalt fiber reinforced inorganic adhesive for concrete strengthening. Adv. Mater. Res. 2011, 287-290, 1197-1200.

17. Dai, J.G.; Munir, S.; Ding, Z. Comparative study of different cement-based ofinorganic paste towards the development of FRIP strengthening of technology. J. Compos. Constr. 2014, 18, doi:10.1061/(ASCE)CC.1943-5614.0000420.

18. Ding, Z.; Li, Z.J. Effect of aggregates and water contents on the propertiesof magnesium phosphor-silicate cement. Cem. Concr. Compos. 2005, 27, 11-18.

19. Tregger, N.; Ferrara, L.; Shah, S.; Pagination, P. Identifying viscosity of cement paste from mini-slump-flow test. ACI Mater. J. 2008, 106, 558-566.

20. Bouvet, A.; Ghorbel, E.; Bennacer, R. The mini-conical slump flow test: Analysis and numerical study. Cem. Concr. Res. 2010, 40, 1517-1523.

(C) 2014 by the authors; licensee MDPI, Basel, Switzerland. This article is an open access article distributed under the terms and conditions of the Creative Commons Attribution license (http://creativecommons.org/licenses/by/4.0/). 